\title{
Pharmacokinetic study of meropenem in healthy beagle dogs receiving intermittent hemodialysis
}
S. Y. BYUN*
J. W. JEONG ${ }^{\dagger}$
J. H. CHOI*
K. P. LEE*
H. Y. YOUN
H. J. $M_{A E N G}{ }^{\S}$
K. H. SONG*
T. S. $\mathrm{KOO}^{\dagger} \&$
K. W. SEO*

*College of Veterinary Medicine, Chungnam National University, Daejeon, Korea; ${ }^{\dagger}$ Graduate School of New Drug Discovery and Development, Chungnam National University, Daejeon, Korea; ${ }^{*}$ Department of Veterinary Internal Medicine, College of Veterinary Medicine, Seoul National University, Seoul, Korea; ${ }^{\S}$ College of Pharmacy, Gachon University, Incheon, Korea
Byun, S. Y., Jeong, J. W., Choi, J. H., Lee, K. P., Youn, H. Y., Maeng, H. J., Song, K. H., Koo, T. S., Seo, K. W. Pharmacokinetic study of meropenem in healthy beagle dogs receiving intermittent hemodialysis. J. vet. Pharmacol. Therap. 39, 560-565.

Meropenem, a second carbapenem antimicrobial agent with a broad spectrum of activity, is used to treat sepsis and resistant-bacterial infections in veterinary medicine. The objective of this study was to identify the pharmacokinetics of meropenem in dogs receiving intermittent hemodialysis (IHD) and to determine the proper dosing in renal failure patients receiving IHD. Five healthy beagle dogs were given a single i.v. dose of $24 \mathrm{mg} / \mathrm{kg}$ of meropenem and received IHD. The blood flow rate, dialysate flow, and ultrafiltration rate were maintained at $40 \mathrm{~mL} / \mathrm{min}, 300 \mathrm{~mL} / \mathrm{min}$, and $40 \mathrm{~mL} / \mathrm{h}$, respectively. Blood samples were collected for $24 \mathrm{~h}$ from the jugular vein and from the extracorporeal arterial and venous line. Urine samples and dialysate were also collected. The concentrations of meropenem were assayed using HPLC/MS/MS determination. The peak plasma concentration was $116 \pm 37 \mu \mathrm{g} / \mathrm{mL}$ at $15 \mathrm{~min}$. The systemic clearance was $347 \pm 117 \mathrm{~mL} / \mathrm{h} / \mathrm{kg}$, and the steady-state volume of distribution was $223 \pm 67 \mathrm{~mL} / \mathrm{kg}$. Dialysis clearance was $71.1 \pm 34.3 \mathrm{~mL} / \mathrm{h} / \mathrm{kg}$, and the extraction ratio by hemodialysis was $0.455 \pm 0.150$. The half-life $\left(T_{1 / 2}\right)$ in dogs with IHD decreased compared with those without IHD, and the reduction in $T_{1 / 2}$ was greater in renal failure patients than in normal patients. Sixty-nine percent and $21 \%$ of the administered drug were recovered by urine and dialysate in the unchanged form, respectively. In conclusion, additional dosing of $24 \mathrm{mg} / \mathrm{kg}$ of meropenem after dialysis could be necessary according to the residual renal function of the patient based on the simulated data.

(Paper received 7 July 2015; accepted for publication 20 April 2016)

Tae-Sung Koo, Graduate School of New Drug Discovery and Development, Chungnam National University, 99 Daehak-ro, Yuseong-gu, Daejeon 305-764,

Korea.E-mail:kootae@cnu.ac.kr

and

Kyoung-Won Seo, College of Veterinary Medicine, Chungnam National University, 99 Daehak-ro, Yuseong-gu, Daejeon 305-764, Korea. E-mail: kwseo@cnu.ac.kr

\section{INTRODUCTION}

Antibiotics are frequently used in patients receiving renal replacement therapy (RRT). According to reports in human medicine, infectious disease and acute kidney injury (AKI) often occur concurrently, and the related mortality is high (Hoste et al., 2006; Roberts et al., 2012). In veterinary medicine, infection is reported as the second most common etiology of AKI (Eatroff et al., 2012), and the incidence of AKI secondary to sepsis is $12 \%$ (Kenney et al., 2010). In renal disease, neutrophil dysfunction can make patients susceptible to infections (Cendoroglo et al., 1999). Therefore, antibiotic use is mandatory in patients with renal failure.
Meropenem is a second carbapenem antimicrobial agent with broad spectrum activity against gram-positive, gramnegative, and anaerobic bacteria (Bidgood \& Papich, 2002). Meropenem is used to treat bacteremia, sepsis, and resistantbacterial infections in veterinary medicine (Papich, 2013). Meropenem has higher activity against Pseudomonas aeruginosa and Enterobacteriaceae than does imipenem in vitro (Jones et al., 1989). It is also stable at dehydropeptidase-1 (DHP-1) and is less nephrotoxic than imipenem, and adverse reactions are rarely observed (Chimata et al., 1993; Hellinger \& Brewer, 1999; Bidgood \& Papich, 2002; Plumb, 2011).

The molecular weight of meropenem is $386.46 \mathrm{Da}$, and meropenem has low-protein binding (11.87\%) and low volume of 
distribution (372 $\pm 53 \mathrm{~mL} / \mathrm{kg}$ ) (Bidgood \& Papich, 2002). These pharmacokinetic properties of meropenem allow it to be readily removed by RRT.

Despite the significance of the pharmacokinetic data for determination of the proper dosing, information about the pharmacokinetics of meropenem in dogs receiving intermittent hemodialysis (IHD) is not available. Therefore, we investigated the pharmacokinetics of meropenem in dogs receiving IHD and determined the proper dosing in renal failure patients receiving IHD.

\section{MATERIALS AND METHODS}

\section{Animals}

Five adult beagle dogs (five males) weighing from 7.94 to $11.4 \mathrm{~kg}$ were included in this study. The dogs were maintained for experimental purposes, housed individually in cages, fed commercial dry food, and given free access to water. All dogs were screened by physical examination, thoracic radiography, complete blood cell count, serum biochemistry, and urinalysis. All dogs were fasted for $12 \mathrm{~h}$ before drug administration and were fed after dialysis. The experiment was conducted in accordance with the Guide for the Care and Use of Laboratory Animals and was approved by Chungnam National University (no.CNU-00526).

\section{Drug administration}

Meropenem trihydrate (Meropen, Yuhan Co., Seoul, Korea) was prepared in normal saline at $20 \mathrm{mg} / \mathrm{mL}$. Dogs were administered a single dose of $24 \mathrm{mg} / \mathrm{kg}$ of meropenem intravenously over a period of $15 \mathrm{~min}$ through the cephalic vein.

\section{Dialysis design}

A 14-French, 15-cm, double-lumen catheter (Hemodialysis catheter, Arrow International) was placed in the right jugular vein under general anesthesia. Anesthesia was induced and maintained with isoflurane (Ifran, Hana Pharm). Catheter placement was performed $24 \mathrm{~h}$ before meropenem infusion.

Hemodialysis was initiated at the end of the infusion and was performed for $5 \mathrm{~h}$ with a $4008 \mathrm{~S}$ dialyzer unit (Fresenius Medicare Care, Homburg, Germany). A pediatric high-flux dialyzer (FX paed; Fresenius Medical Care) was used as an artificial kidney, its membrane material was helixone, and the effective surface area was $0.2 \mathrm{~m}^{2}$. The total blood volume processed was $12 \mathrm{~L}$, and the blood flow rate $(\mathrm{Qb})$ was maintained at $40 \mathrm{~mL} / \mathrm{min}$. The dialysate flow rate $(\mathrm{Qd})$ was $300 \mathrm{~mL} / \mathrm{min}$. The ultrafiltration rate was $40 \mathrm{~mL} / \mathrm{h}$, and the target volume was $200 \mathrm{~mL}$. The anticoagulation agent was heparin, and the target ACT was 180-200 sec.

\section{Sampling}

Blood samples $(<2 \mathrm{~mL})$ were collected from the jugular vein at $0,0.083,0.5,1,2,3,4,5,6,8,12,18$, and $24 \mathrm{~h}$ after infusion. Additionally, blood samples were collected from arterial and venous lines of the extracorporeal circuit at 0, 0.083, 0.5, $1,2,3,4$, and $5 \mathrm{~h}$ after the end of infusion. Blood samples were collected in heparinized tubes and were centrifuged at $1000 \times \boldsymbol{g}$ for $10 \mathrm{~min}$ and kept at $-80{ }^{\circ} \mathrm{C}$ until analysis. Urine samples were collected through urinary catheter in three periods: from 0 to 2,2 to 5 , and 5 to $12 \mathrm{~h}$ after the end of infusion. Spent dialysate was collected in a 100-L plastic barrel, and a representative sample $(1.5 \mathrm{~mL})$ was collected in an Eppendorf tube. The total spent dialysate volume was calculated from the dialysate flow. All samples were immediately stored at $-80{ }^{\circ} \mathrm{C}$ and protected from light until analysis.

\section{Analytical method}

An aliquot $(50 \mu \mathrm{L})$ of internal standard solution (cephalexin $1 \mu \mathrm{g} / \mathrm{mL}$ in acetonitrile) and $200 \mu \mathrm{L}$ of acetonitrile were added to an aliquot $(50 \mu \mathrm{L})$ of plasma to induce the precipitation of plasma proteins. For the diluted urine and dialysate samples, $400 \mu \mathrm{L}$ of acetonitrile was added. Separation was achieved using a HILIC Silica (Waters Atlantis, $3 \mu \mathrm{m}, 2.1 \times 50 \mathrm{~mm}$ ) column with an isocratic mobile phase comprising $0.2 \%$ formic acid in 40:60 ( $/ \mathrm{v})$ water:acetonitrile, and detection was performed using a tandem quadrupole mass spectrometer (API 4000; Applied Biosystems/MDS SCIEX, Foster City, CA, USA) by multiple-reaction monitoring via an electrospray ionization source at $\mathrm{m} / \mathrm{z} 684.2$ to 141.0 for meropenem and $\mathrm{m} / \mathrm{z} 348.2$ to 158.1 for cephalexin. The quantifiable range for plasma samples was from 0.01 to $10 \mu \mathrm{g} / \mathrm{mL}$ with a coefficient of variation (CV) less than $14.3 \%$ and relative error (RE) less than $11.9 \%$ except $0.01 \mathrm{ng} / \mathrm{mL}(18.2 \%)$. In the case of urine, the quantifiable range was from 0.03 to $30 \mu \mathrm{g} / \mathrm{mL}$ with CV less than $7.46 \%$ and RE less than $11.0 \%$. In the case of dialysate, the quantifiable range was from 0.01 to $1 \mu \mathrm{g} / \mathrm{mL}$ with $\mathrm{CV}$ less than $12.0 \%$ except $0.01 \mathrm{ng} / \mathrm{mL}(19.8 \%)$ and RE less than $11.2 \%$. The recovery was over $95 \%$ in all matrixes. Like Huang's report (Huang et al., 2014), significant matrix effect was observed in all matrices (11.4, 19.1 and $16.6 \%$ in plasma, urine, and dialysate, respectively) but that effect did not affect the result. The retention times of meropenem and cephalexin were $1.89 \mathrm{~min}$ and $0.84 \mathrm{~min}$, respectively.

\section{Pharmacokinetic analysis}

The plasma concentration-time profile for each dog was analyzed using the WinNonlin 4.1 (Pharsight) program to determine the pharmacokinetic parameters. To determine the optimal model and weight schemes, values determined with Akaike's information criterion (AIC) and Schwarz Bayesian Criterion (SBC) were compared. Goodness of fit was assessed statistically by the F-test.

Renal clearance $\left(\mathrm{CL}_{R}\right)$ and dialysis clearance $\left(\mathrm{CL}_{D}\right)$ were calculated as

$$
\mathrm{CL}_{R \text { or D }}=\text { Amount }_{\text {urine or dialysate }} / \mathrm{AUC}_{0-\infty}
$$

$\mathrm{CL}_{\mathrm{D}}$ and the extraction ratio by hemodialysis (ERD) were calculated by the following equations (Qp: pumping rate for 
plasma, calculated as $\mathrm{Qb} *$ (1-Hematocrit ratio). $\mathrm{C}_{A}$ : Concentration of arterial line. $\mathrm{C}_{V}$ : Concentration of venous line. Quf: Ultrafiltration rate. Qb: Blood flow rate.) (Gotch, 1976).

$$
\begin{gathered}
\mathrm{CL}_{D}=\left[\mathrm{Qp} \cdot C_{A}-(\mathrm{Qp}-\mathrm{Quf}) \cdot C_{V}\right] / C_{A} \\
\mathrm{ERD}=\mathrm{CL}_{D} /[\mathrm{Qp}+(\mathrm{Qp}-\mathrm{Quf})] / 2
\end{gathered}
$$

Only values during IHD were used for the pharmacokinetic analysis, and the parameters were calculated for each animal and then averaged.

\section{Determination of dosage regimen}

Plasma concentrations were simulated to determine the meropenem dosage regimen, based on mean plasma concentrationtime profiles. A $\mathrm{y}^{2}$-weighted two-compartment model was used to analyze results at a constant rate of intravenous infusion and with first-order output. In calculating CL for anuric renal failure and IHD, the value of $\mathrm{CL}_{R}$ and $\mathrm{CL}_{D}$ was subtracted and added, respectively. The change of renal function and the application of hemodialysis were assumed to affect the elimination rate constant $\left(k_{\mathrm{el}}\right)$ alone.

For antimicrobial effect of carbapenem drugs, the amount of time that the free drug concentration remains above MIC (T $>$ MIC) should be $33-40 \%$ of the drug (Drusano \& Hutchison, 1995; Mouton et al., 2000). Due to the lack of minimal inhibitory concentration (MIC) data for meropenem in veterinary medicine, the MIC value for meropenem in humans was used. Considering its resistance against infection, such as with Pseudomonas, and the difference in plasma protein binding (PPB) between dog and human, the MIC of meropenem in dogs was regarded as $1.1 \mu \mathrm{g} / \mathrm{mL}$.

\section{RESULTS}

The total amount of meropenem administered to each dog was $230 \pm 40 \mathrm{mg}$. No adverse events were observed after the administration of meropenem.

The average plasma concentration-time profiles of meropenem are described in Fig. 1. There was a multi-exponential decline in the plasma meropenem level, and plasma meropenem was no longer detected in any dogs $12 \mathrm{~h}$ after the end of infusion. Analysis showed that a three-compartment model at a constant rate of intravenous infusion did not fit the concentration data. Based on the values obtained from the sum of weighted residual squares, as well as AIC and SBC criteria, of one- and two-compartment model analyses, the two-compartment model with a constant rate of intravenous infusion was determined to optimally fit the plasma concentration data (Table 1). An F-test also showed that the $\mathrm{y}^{2}$-weighted twocompartment model was superior to other models (data not shown).

The pharmacokinetic data using $\mathrm{y}^{2}$-weighted two-compartment model with constant rate intravenous infusion and

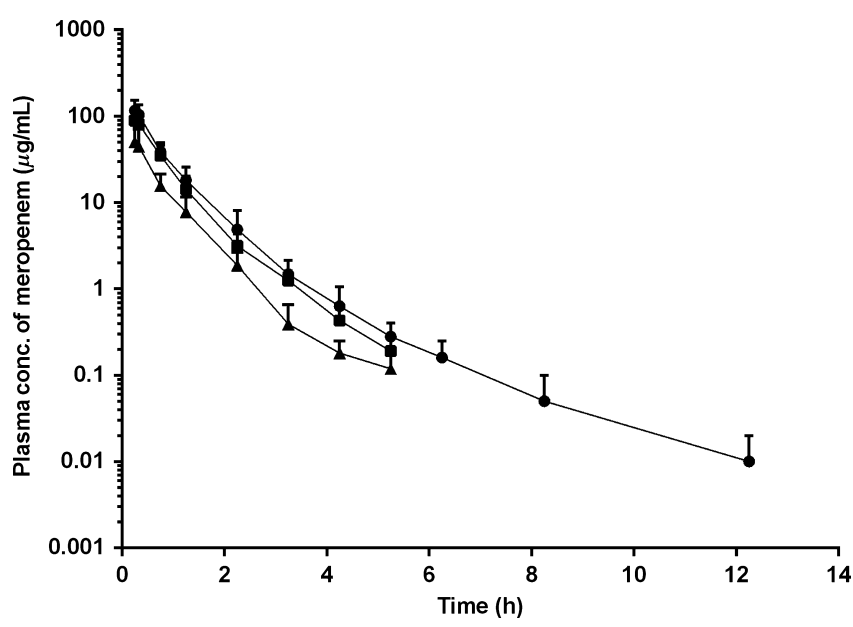

Fig. 1. Mean plasma meropenem concentrations in five beagle dogs on IHD after intravenous administration of meropenem $(24 \mathrm{mg} / \mathrm{kg})$.

- Jugular vein. $\square$ Arterial line. $\mathbf{\Delta}$ Venous line.

constant rate intravenous infusion are described in Table 1. After the i.v. infusion of meropenem, the peak plasma concentration $\left(C_{\max }\right)$ was $116 \pm 37 \mu \mathrm{g} / \mathrm{mL}$ at $15 \mathrm{~min}$. The mean systemic plasma clearance (CL) was $347 \pm 117 \mathrm{~mL} / \mathrm{h} / \mathrm{kg}$, and the mean steady-state volume of distribution $\left(V_{\mathrm{ss}}\right)$ was $223 \pm 67 \mathrm{~mL} / \mathrm{kg}$.

The mean amount of meropenem in urine in the first $2 \mathrm{~h}$ after the end of infusion was $142 \pm 90 \mathrm{mg}$; for $0-5 \mathrm{~h}$, it was $158 \pm 71 \mathrm{mg}$; and for $0-12 \mathrm{~h}$, it was $159 \pm 72 \mathrm{mg}$. The main proportion $(68.9 \%)$ of the administered drug was excreted by the urine in an unchanged form, and $89.2 \%$ of the urine excretion occurred in the first $2 \mathrm{~h}$. The mean amount of meropenem recovered from the dialysate was $47.2 \pm 22.8 \mathrm{mg}$, and this value was approximately $20.5 \%$ of the administered drug. Based on the concentration of meropenem in the dialysate, dialysis clearance $\left(\mathrm{CL}_{D}\right)$ was calculated as $71.1 \pm$ $34.3 \mathrm{~mL} / \mathrm{h} / \mathrm{kg}$. As calculated using the method of Gotch, $\mathrm{CL}_{D}$ was $65.4 \pm 27.5 \mathrm{~mL} / \mathrm{h} / \mathrm{kg}$. The mean ERD value was $0.455 \pm 0.150$.

Table 2 shows the clearance and elimination half-life in dogs with various degrees or renal functions with/without IHD. Calculations were based on the pharmacokinetic data from average concentration and performed using on equations 4 ( $k_{\mathrm{el}}$ : elimination rate constant)

$$
T_{1 / 2}=\ln 2 / k_{\mathrm{el}}
$$

Group 1 included healthy beagle dogs with normal renal function; the clearance of meropenem was $276 \mathrm{~mL} / \mathrm{h} / \mathrm{kg}$, and $T_{1 / 2}$ was $1.14 \mathrm{~h}$. If IHD were applied to this group, $T_{1 / 2}$ would decrease to $80 \%$ of $T_{1 / 2}$ compared with the value for group 1 during the dialysis period. Assuming an anuric state of renal failure, additional clearance of the dialyzer would increase the total clearance more than twofold compared with the $26 \%$ increase observed in groups with normal renal function. Accordingly, the dialysis clearance of meropenem 
Table 1. Pharmacokinetic parameters of meropenem in healthy beagle dogs after intravenous infusion of meropenem (24 mg/kg for $0.25 \mathrm{~h})$ during IHD

\begin{tabular}{|c|c|c|c|c|c|c|c|}
\hline PK Parameters & Dog 1 & $\operatorname{Dog} 2$ & Dog 3 & $\operatorname{Dog} 4$ & Dog 5 & Mean \pm S.D. & Mean Conc. \\
\hline $\mathrm{C}_{\max }(\mu \mathrm{g} / \mathrm{mL})$ & 163 & 124 & 70.2 & 90.0 & 135 & $116 \pm 37$ & 116 \\
\hline $\operatorname{AUC}_{0-\infty}(\mu \mathrm{g} \cdot \mathrm{h} / \mathrm{mL})$ & 116 & 81.6 & 49.1 & 59.1 & 87.9 & $78.8 \pm 26.3$ & 79.8 \\
\hline $\mathrm{CL}(\mathrm{mL} / \mathrm{h} / \mathrm{kg})$ & 215 & 307 & 509 & 423 & 285 & $347 \pm 117$ & 313 \\
\hline
\end{tabular}

$\mathrm{T}_{\max }=$ Time until maximum concentration. $\mathrm{C}_{\max }=$ Maximum concentration. $T_{1 / 2}=$ Elimination half-life. AUC $=$ Area under the curve. $\mathrm{MRT}=$ Mean residence time. $\mathrm{CL}=$ Clearance. $V_{\mathrm{ss}}=$ Apparent volume of distribution.

*Harmonic mean.

Table 2. Prediction of the elimination half-life based on pharmacokinetic data from average concentration

\begin{tabular}{llll}
\hline Group & \multicolumn{1}{c}{ Condition } & \multicolumn{1}{c}{$\begin{array}{c}\text { Final Clearance } \\
(\mathrm{mL} / \mathrm{h} / \mathrm{kg})\end{array}$} & $\begin{array}{c}\text { Half-life } \\
\text { during IHD }(\mathrm{h})\end{array}$ \\
\hline 1 & Normal without IHD & $\mathrm{CL}_{R}+\mathrm{CL}_{\text {others }}$ & 1.14 \\
& & $216+37=249$ & $\left(T_{1 / 2}\right)$ \\
2 & \multirow{2}{*}{ Normal with IHD } & $\mathrm{CL}_{R}+\mathrm{CL}_{\text {others }}$ & 0.81 \\
& & $216+33+64=313$ & $\left(0.8 \cdot T_{1 / 2}\right)$ \\
3 & Anuric renal failure & $\mathrm{CL}_{\text {others }}$ & 5.59 \\
& & 33 & $\left(7.5 \cdot T_{1 / 2}\right)$ \\
4 & Anuric renal failure & $\mathrm{CL}_{\text {others }}+\mathrm{CL}_{D}$ & 2.90 \\
& with IHD & $33+64=97$ & $\left(2.6 \cdot T_{1 / 2}\right)$ \\
\hline
\end{tabular}

$\mathrm{CL}_{R}=$ Renal clearance. $\mathrm{CL}_{\mathrm{other}}=$ Nonrenal clearance. $\mathrm{CL}_{D}=$ Dialysis clearance. $T_{1 / 2}=$ Elimination half-life.

would be expected to account for $65.7 \%$ of the total clearance in the anuric renal failure group. However, applying IHD treatment to anuric renal failure patients would cause a significant decrease in $T_{1 / 2}$ from $8.5 \mathrm{~h}$ to $2.9 \mathrm{~h}$ during the dialysis period

The pharmacokinetic simulations of the plasma-time concentration profile of meropenem in dogs with various renal functions and with/without IHD are described in Fig. 2.

\section{DISCUSSION}

A dosing simulation was performed based on the data from our study to assess the adequacy of adjusting the general dosage regimens in IHD dogs and to establish dose recommendations in renal patients receiving IHD.

Previous pharmacokinetic studies of meropenem have been performed in healthy beagle dogs (Harrison et al., 1989; Bidgood \& Papich, 2002). In our study, the total body clearance, plasma half-life, area under curve (AUC), and volume of distribution are similar to the values determined in previous studies. According to Bidgood et al., after $20 \mathrm{mg} / \mathrm{kg}$ meropenem infusion, the total body clearance was $392 \pm 91 \mathrm{~mL} / \mathrm{h} / \mathrm{kg}$, and the plasma half-life was $0.67 \pm 0.07 \mathrm{~h}$. The AUC and volume of distribution were $53 \pm 12 \mu \mathrm{g} \cdot \mathrm{h} / \mathrm{mL}$ and $337 \pm 52 \mathrm{~mL} / \mathrm{kg}$, respectively.

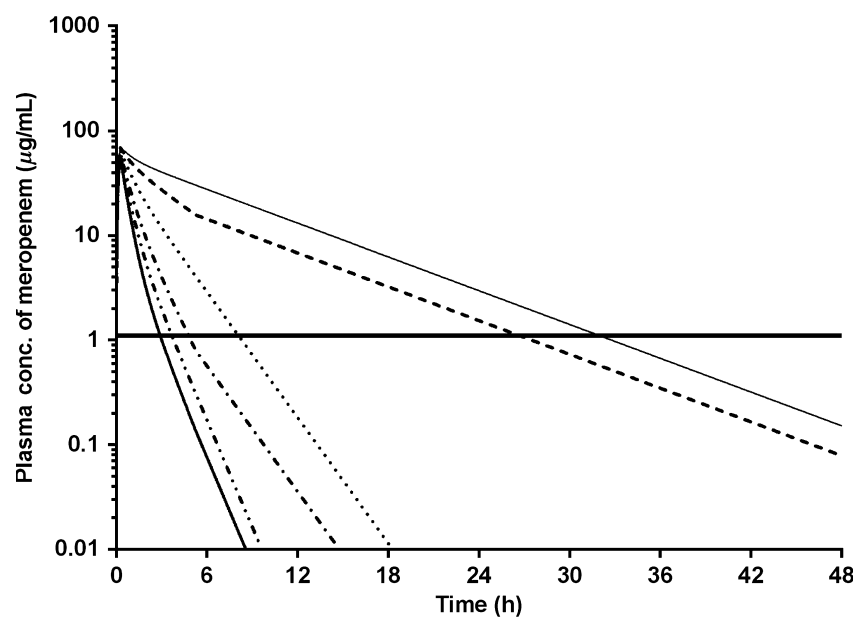

Fig. 2. Simulated mean plasma-time concentration profile of meropenem (single dose, $24 \mathrm{mg} / \mathrm{kg}$, i.v.) in dogs with normal renal function + IHD (—), normal renal function (—. - -), 75\% renal failure + IHD (—- -), 75\% renal failure (…..), 100\% renal failure + IHD (- - - -), and $100 \%$ renal failure (-).

Drug removal through hemodialysis was first reported by Golper et, al (Golper et al., 1985). Thereafter, numerous studies of drug removal during $\mathrm{HD}$ have been performed in human medicine. Considerations for drug dosing in patients under renal replacement therapy are including drug characteristics, HD prescription, and patients' status. Drug with low-protein binding, low volume of distribution, and low molecular weight and size can be significantly removed through dialyzers (Bohler et al., 1999; Heintz et al., 2009).

In humans, meropenem and its metabolite showed significant removal through IHD, and the possibility of underdosing was reported (Thalhammer \& Horl, 2000). Several studies confirmed a significant decrease in the elimination half-life during dialysis, and the reported drug removal comprised as much as $50-70 \%$ of the administered drug (Leroy et al., 1992a,b). Additional dosing of meropenem at the end of dialysis is recommended in these studies to avoid underdosing (Christensson et al., 1992; Leroy et al., 1992a,b; Chimata et al., 1993).

Meropenem removal through IHD using a helixone membrane was identified in this study. Dialysis clearance was 
calculated from the measurement of the meropenem concentration in the recovered dialysate and was calculated using the method of Gotch (Gotch, 1976). The two clearances were similar, and approximately $20.5 \%$ of the administered meropenem was removed by the dialyzer.

In general, serious renal failure reduces plasma protein binding. However, the PPB of meropenem in dogs was reported to be about 11\% (Bidgood \& Papich, 2002), suggesting that altered protein binding had negligible impact on renal failure and hemodialysis. Furthermore, renal dysfunction would be expected to cause decreased drug clearance proportionally to the residual renal function, and the dogs on IHD showed decreased $T_{1 / 2}$ and low plasma concentrations compared with those observed in off-dialysis dogs with the same renal function.

According to this simulation, the dosage regimen of $24 \mathrm{mg} / \mathrm{kg}$, i.v., once daily is inadequate in both the on- and off-dialysis groups with normal renal function. In dogs with normal renal function, i.v. infusion of $24 \mathrm{mg} / \mathrm{kg}$ of meropenem every $8 \mathrm{~h}$ was adequate, regardless of the IHD treatment. In off-dialysis dogs whose renal function has failed by up to $75 \%, 24 \mathrm{mg} / \mathrm{kg}$ of meropenem once daily maintains its plasma concentration for sufficient time, but not in on-dialysis dogs. Applying the same interval to the IHD dogs would result in an underdosing of meropenem because T>MIC does not exceed $40 \%$ of the dosing interval. Therefore, repetitive dosing of $24 \mathrm{mg} / \mathrm{kg}$ of meropenem after IHD may be required in these dogs. In contrast to dogs with $75 \%$ renal failure, anuric patients with IHD do not require meropenem re-dosing. In accordance with this simulation, $24 \mathrm{mg} / \mathrm{kg}$ of meropenem every $72 \mathrm{~h}$ would be sufficient to obtain a bacterial killing effect in anuric, off-dialysis dogs, and applying the same dosage to anuric patients receiving IHD would also be sufficient. Therefore, re-dosing in anuric dogs receiving $\mathrm{IHD}$ is not necessary.

As noted above, IHD treatment does not always correlate to re-dosing of meropenem in dogs, unlike in the human dosing guidelines. The necessity of repetitive dosing did not show consistency among groups, and this difference is thought to be caused by the residual renal function of the patient. A previous study reported the influence of the residual renal function of the patient on meropenem clearance (Isla et al., 2005). It was explained that even with the dialysis clearance of meropenem, renal clearance was the major route of elimination of the drug, and drug clearance could be influenced significantly by the patient's renal function.

However, recent studies in human patients reported that maintaining $\mathrm{T}>\mathrm{MIC}$ at $33-40 \%$ of the dosing interval did not achieve the desired antimicrobial effects. In one study, optimal clinical outcomes were achieved when $\mathrm{T}>\mathrm{MIC}$ was maintained at over $75 \%$ of the dosing interval (Ariano et al., 2005), suggesting that the dosage regimens used in our study were insufficient. Further pharmacodynamic studies are required to assess the antimicrobial effect of meropenem and relationship between $\mathrm{T}>\mathrm{MIC}$ and bacterial killing effect in vivo.

This study is limited to the specific settings of IHD (blood flow, ultrafiltration rate, dialyzer membrane) and was conducted in healthy subjects; therefore, meropenem removal could be altered in different settings of IHD and in actual patients with different renal function.In addition, dosing requirements can vary in individual patients, as the simulated data are based on average plasma concentrations.

Multiple-dosing studies in patients with various degrees of renal failure at different IHD settings should be performed to obtain a conclusive recommendation for a dosage regimen.

\section{CONCLUSIONS}

This study investigated the pharmacokinetics of meropenem in healthy beagle dogs receiving IHD. Meropenem removal through IHD was identified, and underdosing occurred. Repetitive dosing of $24 \mathrm{mg} / \mathrm{kg}$ of meropenem after dialysis could be required depending on the residual renal function of the patient.

\section{CONFLICT OF INTERESTS}

The authors declare that they have no conflict of interests.

\section{ACKNOWLEDGMENTS}

This research was supported by Basic Science Research Program through the National Research Foundation of Korea (NRF) funded by the Ministry of Education (NRF2014R1A1A4A01007297).

\section{REFERENCES}

Ariano, R.E., Nyhlen, A., Donnelly, J.P., Sitar, D.S., Harding, G.K. \& Zelenitsky, S.A. (2005) Pharmacokinetics and pharmacodynamics of meropenem in febrile neutropenic patients with bacteremia. The Annals of Pharmacotherapy, 39, 32-38.

Bidgood, T. \& Papich, M.G. (2002) Plasma pharmacokinetics and tissue fluid concentrations of meropenem after intravenous and subcutaneous administration in dogs. American Journal of Veterinary Research, 63, 1622-1628.

Bohler, J., Donauer, J. \& Keller, F. (1999) Pharmacokinetic principles during continuous renal replacement therapy: drugs and dosage. Kidney International. Supplement, 72, S24-S28.

Cendoroglo, M., Jaber, B.L., Balakrishnan, V.S., Perianayagam, M., King, A.J. \& Pereira, B.J. (1999) Neutrophil apoptosis and dysfunction in uremia. Journal of the American Society of Nephrology: JASN, 10, 93-100.

Chimata, M., Nagase, M., Suzuki, Y., Shimomura, M. \& Kakuta, S. (1993) Pharmacokinetics of meropenem in patients with various degrees of renal function, including patients with end-stage renal disease. Antimicrobial Agents and Chemotherapy, 37, 229-233.

Christensson, B.A., Nilsson-Ehle, I., Hutchison, M., Haworth, S.J., Oqvist, B. \& Norrby, S.R. (1992) Pharmacokinetics of meropenem in subjects with various degrees of renal impairment. Antimicrobial Agents and Chemotherapy, 36, 1532-1537.

Drusano, G.L. \& Hutchison, M. (1995) The pharmacokinetics of meropenem. Scandinavian Journal of Infectious Diseases. Supplementum, 96, $11-16$. 
Eatroff, A.E., Langston, C.E., Chalhoub, S., Poeppel, K. \& Mitelberg, E. (2012) Long-term outcome of cats and dogs with acute kidney injury treated with intermittent hemodialysis: 135 cases (19972010). Journal of the American Veterinary Medical Association, 241, 1471-1478.

Golper, T.A., Pulliam, J. \& Bennett, W.M. (1985) Removal of therapeutic drugs by continuous arteriovenous hemofiltration. Archives of Internal Medicine, 145, 1651-1652.

Gotch, F.A. (1976) The kidney. The W.B. Saunders Co., Philadelphia.

Harrison, M.P., Moss, S.R., Featherstone, A., Fowkes, A.G., Sanders, A.M. \& Case, D.E. (1989) The disposition and metabolism of meropenem in laboratory animals and man. The Journal of Antimicrobial Chemotherapy, 24 (Suppl. A), 265-277.

Heintz, B.H., Matzke, G.R. \& Dager, W.E. (2009) Antimicrobial dosing concepts and recommendations for critically ill adult patients receiving continuous renal replacement therapy or intermittent hemodialysis. Pharmacotherapy, 29, 562-577.

Hellinger, W.C. \& Brewer, N.S. (1999) Carbapenems and monobactams: imipenem, meropenem, and aztreonam. Mayo Clinic Proceedings, 74, 420-434.

Hoste, E.A., Clermont, G., Kersten, A., Venkataraman, R., Angus, D.C., De Bacquer, D. \& Kellum, J.A. (2006) RIFLE criteria for acute kidney injury are associated with hospital mortality in critically ill patients: a cohort analysis. Critical Care, 10, R73.

Huang, L., Haagensen, J., Verotta, D., Lizak, P., Aweeka, F. \& Yang, K. (2014) Determination of meropenem in bacterial media by LC-MS/ MS. Journal of Chromatography B, Analytical Technologies in the Biomedical and Life Sciences, 961, 71-76.

Isla, A., Maynar, J., Sanchez-Izquierdo, J.A., Gascon, A.R., Arzuaga, A., Corral, E. \& Pedraz, J.L. (2005) Meropenem and continuous renal replacement therapy: in vitro permeability of 2 continuous renal replacement therapy membranes and influence of patient renal function on the pharmacokinetics in critically ill patients. Journal of Clinical Pharmacology, 45, 1294-1304.
Jones, R.N., Barry, A.L. \& Thornsberry, C. (1989) In-vitro studies of meropenem. The Journal of Antimicrobial Chemotherapy, 24 (Suppl. A), 9-29.

Kenney, E.M., Rozanski, E.A., Rush, J.E., deLaforcade-Buress, A.M., Berg, J.R., Silverstein, D.C., Montealegre, C.D., Jutkowitz, L.A., Adamantos, S., Ovbey, D.H., Boysen, S.R. \& Shaw, S.P. (2010) Association between outcome and organ system dysfunction in dogs with sepsis: 114 cases (2003-2007). Journal of the American Veterinary Medical Association, 236, 83-87.

Leroy, A., Fillastre, J.P., Borsa-Lebas, F., Etienne, I. \& Humbert, G. (1992a) Pharmacokinetics of meropenem (ICI 194,660) and its metabolite (ICI 213,689) in healthy subjects and in patients with renal impairment. Antimicrobial Agents and Chemotherapy, 36, 27942798.

Leroy, A., Fillastre, J.P., Etienne, I., Borsa-Lebas, F. \& Humbert, G. (1992b) Pharmacokinetics of meropenem in subjects with renal insufficiency. European Journal of Clinical Pharmacology, 42, 535-538.

Mouton, J.W., Touzw, D.J., Horrevorts, A.M. \& Vinks, A.A. (2000) Comparative pharmacokinetics of the carbapenems: clinical implications. Clinical Pharmacokinetics, 39, 185-201.

Papich, M.G. (2013) Antibiotic treatment of resistant infections in small animals. The Veterinary clinics of North America Small Animal Practice, 43, 1091-1107.

Plumb, D.C. (2011) Plumb's Veterinary Drug Handbook, 7th edn, Pharma Vet Inc., Stockholm, Wiscosin.

Roberts, D.M., Roberts, J.A., Roberts, M.S., Liu, X., Nair, P., Cole, L., Lipman, J., Bellomo, R. \& Investigators, R.R.T.S. (2012) Variability of antibiotic concentrations in critically ill patients receiving continuous renal replacement therapy: a multicentre pharmacokinetic study. Critical Care Medicine, 40, 1523-1528.

Thalhammer, F. \& Horl, W.H. (2000) Pharmacokinetics of meropenem in patients with renal failure and patients receiving renal replacement therapy. Clinical Pharmacokinetics, 39, 271-279. 